\title{
Differential display analysis of gene expression accompanied by neurite outgrowth of human neuroblastoma Cell IMR32 using non-gel molecular sieving capillary electrophoresis
}

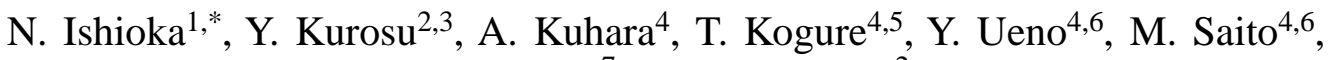 \\ K. Watabe ${ }^{7}$ and I. Nagaoka ${ }^{2}$ \\ ${ }^{1}$ Space Utilization Systems, Tsukuba Space Center, National Space Development Agency of Japan (NASDA), \\ 2-1-1, Sengen, Tsukuba-shi, Ibaraki 305-8505, Japan \\ ${ }^{2}$ The department of Biochemistry, Juntendo University, School of Medicine, 2-1-1, \\ Hongo, Bunkyo-ku, Tokyo 113-0033, Japan \\ ${ }^{3}$ JASCO Technical Research Laboratories Corporation, 2097-2, Ishikawa-cho, \\ Hachioji-shi, Tokyo 192-0032, Japan \\ ${ }^{4}$ Division of Molecular Cell Biology, Institute of DNA Medicine, The Jikei university School of Medicine, \\ 3-25-8, Nishi-Shinbashi, Minato-ku, Tokyo 105-0003, Japan \\ ${ }^{5}$ Department of Neuro Surgery, The Jikei university School of Medicine, 3-25-8, Nishi-Shinbashi, \\ Minato-ku, Tokyo 105-0003, Japan \\ ${ }^{6}$ Department of Orthopedic Surgery, The Jikei university School of Medicine, 3-25-8, Nishi-Shinbashi, \\ Minato-ku, Tokyo 105-0003, Japan \\ ${ }^{7}$ Department of Neuropathology, Tokyo Metropolitan Institute for Neuroscience, 2-6, Musashidai,
} Fuchu-shi, Tokyo 183-0042, Japan

\begin{abstract}
The induced proliferative response of the human derived neuroblastoma cell (IMR32), with the cell proliferation mediating factor, is much milder compared to other cell strains, and develops cellular clusters which are characterized by numerous extensions of dendrites. Presuming this phenomenon to be one of the induced neuronal differentiation due to genetic alterations, we preliminary studied to elucidate the changes in gene expression of the IMR32 by mRNA differential display analysis, monitoring polymerase chain reaction (PCR) products by non-gel molecular sieving capillary electrophoresis in linear polyacrylamide solution. The CE fingerprints revealed a number of peaks with differential expression patterns.
\end{abstract}

Keywords. Differential display - RT-PCR - neuroblastoma - cell proliferation - capillary electrophoresis - molecular sieving linear polyacrylamide.

\section{Introduction}

Most cell proliferation, differentiation, and other developmental processes are characterized by changes in gene expression. Identification of such changes is very important to understand the gene regulatory mechanism. Several polymerase chain reaction (PCR)-based methods have been offered to identify such differential changes [1-10]. One of the developmental techniques of such methods is a mRNA differential display $[3,4,6,9,10]$ which consists of two steps. The first step is the reverse transcription of total cellular RNA to single-strand cDNA using a 3'-anchored oligo-dT primer. The second step is the amplification of a subset of
cDNAs using the same 3 '-anchored primer and an arbitrary primer. The rapid analysis for the differences in expression between different cell types would require a highly reproducible system for peak patterns of PCR products. Currently, the slab gel electrophoresis is used, and band patterns are detected by autoradiographs or fluorescent stains in agarose and/or polyacrylamide gels. It takes relatively long time to get results and scanning of band patterns is also very time consuming. Furthermore the PCR enables the amplification of specific cDNAs that are often present in trace amounts of biological material, therefore a high-resolution tool which provides an alternative to conventional slab gel electrophoresis is required for the analysis of the PCR products.

* Correspondence and reprints

Received July 15, 1998; revised February 05, 1999; accepted February 08, 1999. 
Capillary electrophoresis (CE), with its high-resolution power, speed, ability to analyze small sample volumes and automation, is a widely utilized technique in the field of life science [11-13] and has great potential for analysis of the PCR products [14-19]. CE also provides the capability for quantitation in real-time and on-line detection, and even fractionation of peaks $[12,13]$. In this study, we attempted to characterize the genetic alterations and employed the molecular sieving $\mathrm{CE}$ in linear polyacrylamide for mRNA fingerprinting and for detecting differentially expressed genes accompanied by neurite outgrowth of human neuroblastoma cell IMR32.

In molecular sieving $\mathrm{CE}$, there are two methods to realize the separation by gel filtration mode. One is to form gel, which is similar to conventional gel, in the capillary as a sieving medium. The other is to pack non-cross-linked medium in the capillary instead of conventional gel to perform gel filtration. In this method, non-branched or branched macromolecule solution such as linear polyacrylamide, cellulose derivatives, dextran are used as sieving media. The greatest advantage of use of non-gel for $\mathrm{CE}$ is that the sieving medium can be changed easily for every run according to analytical requirements. Considering the feature, it is expected that $\mathrm{CE}$ using non-gel as sieving media will be more commonly used in the future.

\section{Experimental}

\section{IMR32 cell culture and induced neuronal differentiation}

Human neuroblastoma IMR32 cells (Dai-Nippon Pharmaceutical Co., Osaka, Japan) were cultured in RPMI1640 medium supplemented with $10 \%$ fetal bovine serum (FBS), $100 \mathrm{U} / \mathrm{mL}$ of penicillin $\mathrm{G}$ and $100 \mu \mathrm{g} / \mathrm{mL}$ of streptomycin in an atmosphere of $5 \% \mathrm{CO}_{2}-95 \%$ air at $37^{\circ} \mathrm{C}$. After the cells reached confluence in RPMI1640 with $10 \%$ FBS, cells were separated in half. Each cell fraction collected by low-speed centrifugation and washed twice with PBS to removed remaining medium components. One of the half was suspended again in RPMI1640 with $10 \%$ FBS and the other was suspended in RPMI1640 with $10 \%$ the cell proliferation mediating factor (Daigo's GF21; Wako, Osaka, Japan) instead of FBS. The GF21 was commercially provided by adding insulin, transferrin, sodium selenite, and ethanolamine for cell growth [19] to adult bovine serum removed predominantly IgM and IgG by ammonium sulfate precipitation. Cells were maintained in these conditions for 7 days without replacement of medium.

\section{Total RNA isolation}

Total RNA was isolated from cultured cells by the RNAzol B RNA isolation kit (TEL-TEST, Inc., Friendwood, TX, USA) according to manufacture's instruction.

\section{mRNA differential display}

The differential display was performed by the mRNA fingerprinting kit (Wako, Osaka, Japan) based on the reported method [9]. Total RNA $(2.5 \mu \mathrm{g})$ was mixed with 50 pmol of 3 '-anchor primer and incubated at $70{ }^{\circ} \mathrm{C}$ for $10 \mathrm{~min}$, and then the reaction mixture $(10 \mu \mathrm{L})$ was chilled on ice for several minutes. To this solution, $10 \mu \mathrm{L}$ of $20 \mathrm{mM}$ Tris- $\mathrm{HCl}$, pH8.4, containing $1 \mathrm{mM}$ dNTPs, $5 \mathrm{mM} \mathrm{MgCl}_{2}, 20 \mathrm{mM}$ DTT and 200 units of reverse transcriptase in the kit was added. The mixture was incubated at $25{ }^{\circ} \mathrm{C}$ for $10 \mathrm{~min}$ and at $42{ }^{\circ} \mathrm{C}$ for $50 \mathrm{~min}$ in thermocycler (ASTEC PROGRAM TEMP CONTROL PC-800; ASTEC, Fukuoka, Japan). At the end of this incubation, the temperature was raised to $70{ }^{\circ} \mathrm{C}$ for $15 \mathrm{~min}$ and then reduced to $4{ }^{\circ} \mathrm{C}$. The reaction mixture (cDNA solution) was diluted with $80 \mu \mathrm{L}$ of $\mathrm{TE}$ buffer (10 mM Tris-HCl/1 mM EDTA, pH7.5) containing $9 \mu \mathrm{l}$ of the same 3 -anchor primer and stored at $-20{ }^{\circ} \mathrm{C}$ until use. One of the arbitrary primers $(0.5 \mu \mathrm{M}$ at final concentration) was added into the reaction mixture $(20 \mu \mathrm{L})$ for PCR which contained $2 \mu \mathrm{L}$ of the cDNA solution described above, $50 \mu \mathrm{M}$ dNTPs and 1 unit of DNA polymerase Gene Taq in the kit. The second strand was synthesized at $95{ }^{\circ} \mathrm{C}$ for $3 \mathrm{~min}, 40{ }^{\circ} \mathrm{C}$ for $5 \mathrm{~min}$ and $72{ }^{\circ} \mathrm{C}$ for $5 \mathrm{~min}$, and the amplification was repeated by 24 cycles of a thermal cycling program which was composed of $95{ }^{\circ} \mathrm{C}$ for $15 \mathrm{sec}, 40{ }^{\circ} \mathrm{C}$ for $2 \mathrm{~min}$ and $72{ }^{\circ} \mathrm{C}$ for $1 \mathrm{~min}$. An additional final extension step was done at $72{ }^{\circ} \mathrm{C}$ for $5 \mathrm{~min}$. The PCR products were cleaned-up and desalted using a Microcon 100 (Amicon, Beverly, MA, USA), according to the reported method [18]. The resulting samples were subjected to CE analysis.

\section{Non-gel molecular sieving capillary electrophoresis in linear polyacrylamide solution}

Capillary electrophoresis (CE) was performed on the JASCO model CE-800 system (JASCO, Tokyo, Japan). A linear polyacrylamide solution-filled, uncoated fused-silica capillary $(75 \mu \mathrm{m}$ i.d., $50 \mathrm{~cm}$ total length, $30 \mathrm{~cm}$ effective length) was prepared as follows. The capillary was filled with $12 \%$ acrylamide in a buffer of $100 \mathrm{mM}$ Tris $/ 250 \mathrm{mM}$ boric acid/7M urea, $\mathrm{pH} 8.1$, containing $0.1 \%$ potassium persulfate (PPS) and $0.1 \% \mathrm{~N}, \mathrm{~N}, \mathrm{~N}^{\prime}, \mathrm{N}^{\prime}$-tetramethylenediamine (TEMED) as polymerization initiator and catalyst, respectively. Both ends of the capillary tube were dipped into the non-gel solution until completely polymerized (c.a. $3 \mathrm{~h}$ ). After polymerization, one end (injection side) of capillary tube was replaced into a buffer $(100 \mathrm{mM}$ Tris $/ 250 \mathrm{mM}$ boric acid, pH8.1) reservoir attached to the negative side of the power supply and the other end (detection side) was placed as it is, in the non-gel solution attached to the positive side, providing new solution through electroosmotic flow. The sample was introduced into the capillary by electrokinetic injection $(-5 \mathrm{kV}$ for $40 \mathrm{~s})$ from the cathode side, and electrophoresis was performed at $-15 \mathrm{kV}$ constant voltage $(-300 \mathrm{~V} / \mathrm{cm})$ for $70 \mathrm{~min}$ at room temperature and was monitored simultaneously at $260 \mathrm{~nm}$ at the anode side. The $\phi x 174$ DNA Hae III digests $(500 \mu \mathrm{g} / \mathrm{mL}$, BRL Labs., Gaithersburg, MD, USA) were used for standard DNA ladder which was dissolved in $10 \mathrm{mM}$ Tris- $\mathrm{HCl}(\mathrm{pH} 9.7)$, $1.0 \mathrm{mM}$ EDTA, $20 \mathrm{mM} \mathrm{NaCl}$. 


\section{Original articles}
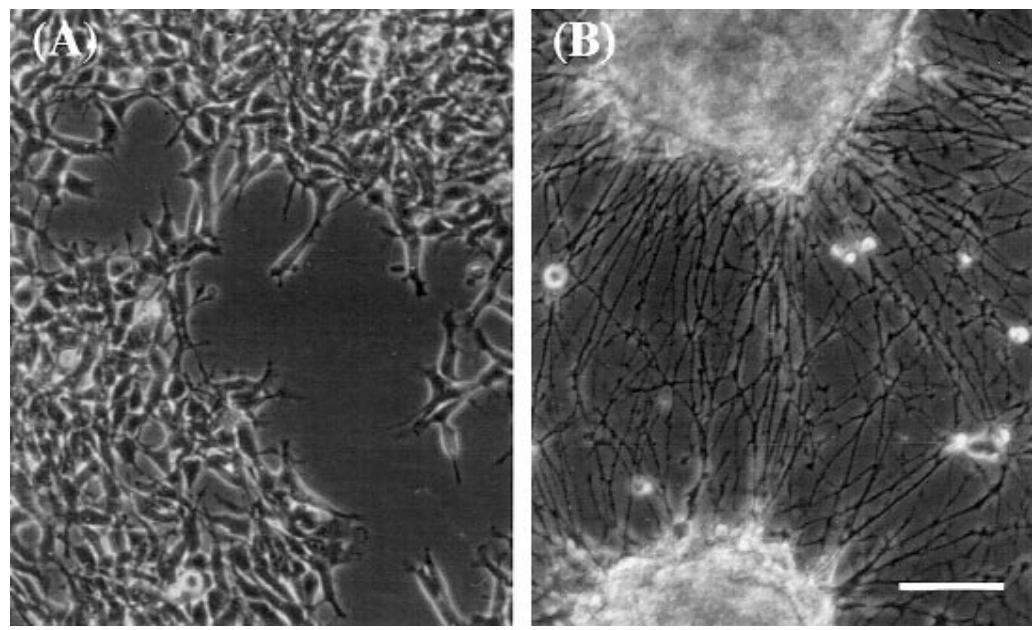

Fig. 1. Phase contrast morphology of IMR32 neuroblastoma cells in FBS-medium (A: left) and in GF21-medium (B: right) after 7 days in culture. Culture in FBS-medium (left) shows clumping of cells without any morphological differentiation. However, the culture in the GF21-medium (right) exhibits clustering of cells with long neurites. White scale bar $=20 \mu \mathrm{m}$.

\section{Results and discussion}

\section{Effects of GF21 on IMR32 cells}

Human neuroblastoma IMR32 cells were cultured 7 days in FBS- and GF21-mediums, and cell numbers were determined after 7 days. On day 7 cell numbers in GF21-medium was about one and third of cell numbers in FBS-medium. Proliferation of IMR32 cells was modest in GF21, although GF21 was commercially sold as a cell proliferation mediating factor. From day 4 onwards, by contrast, the effect of GF21 on cell differentiation in term of neurite outgrowth became obvious, and the culture displayed quite different morphologies after 7 days (Fig. 1B). In GF21-medium, IMR32 cell bodies formed large clusters and grew a dense network of neuritic processes. From the cluster with cell aggregates, long and thick fiber bundles extended and contacted other cell clusters. Under FBS-medium, changes in cellular morphologies were not apparent on day 7 (Fig. 1A). These results presumes that the morphological change on IMR32 cultured in GF21-medium was one of induced neuronal differentiation.

\section{Analysis of mRNA differential display by molecular sieving $C E$}

The CE electrophoregram of the $\phi x 174$ DNA Hae III digests for standard DNA ladder was shown in figure 2. The CE conditions were designed to enhance the separation efficiency for fragments in the $72-872$ bp range, because, according to the instruction of the kit, DNA polymerase gene Taq in the kit was suitable for amplification of the cDNA ranging from 100 to $800 \mathrm{bp}$ in this study. The R.S.D. values of migration and peak areas for $194 \mathrm{bp}$ fragment, were $0.60 \%(n=5)$ and $1.30(n=5)$, respectively. Thus, this separation system produced highly reproducible results, and was a useful tool for DNA analysis [20].

A series of primer combinations were utilized to generate gene expression profiles for normal cells and morpho-

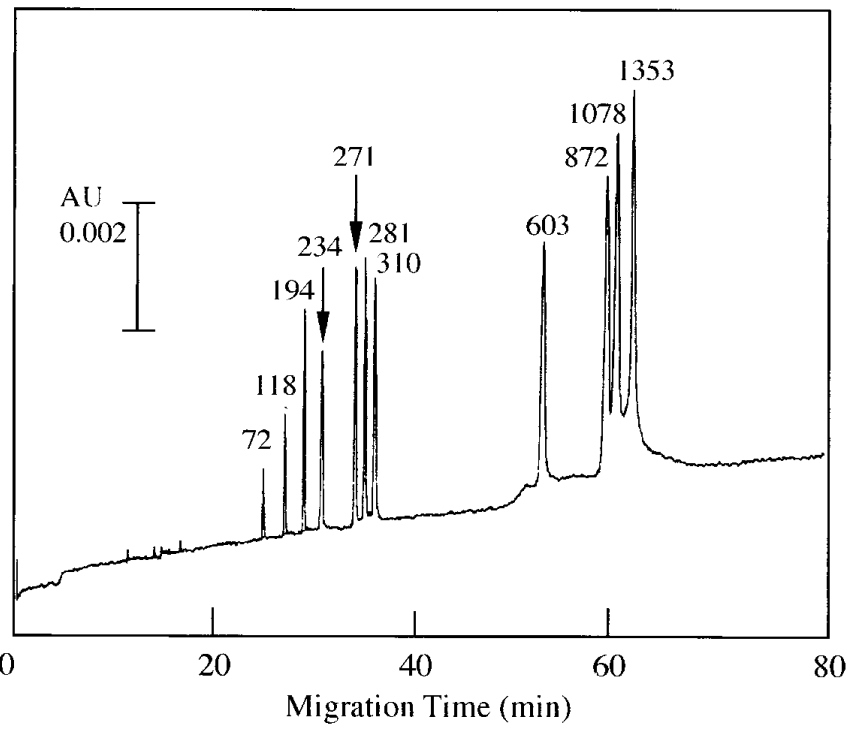

Fig. 2. Separation of the $\phi x 174$ DNA Hae III digests for standard DNA ladder. Electrophoretic conditions are described in the Experimental session. The numbers of peak tops indicates the base pairs of each digest.

logically changed cells. The three sets of primers are shown in figure 3 as examples. Examination of these CE patterns revealed many developmental changes in gene expression and some of these were indicated. Total 51 amplicon peaks in figure were indicated, and the $41.2 \%$ of the total amplicons was diminished and $19.6 \%$ was enhanced in morphologically changed cells. The expression of the others $(39.2 \%)$ was essentially constant at each cell. The enhanced amplicons were most prominent in the morphologically changed cells and were absent in the normal cells. Especially, a new peak, which was an about 260 bp amplicon (an asterisk in Fig. 3), possibly was a candidate for differentially expressed gene. However, for morphological 

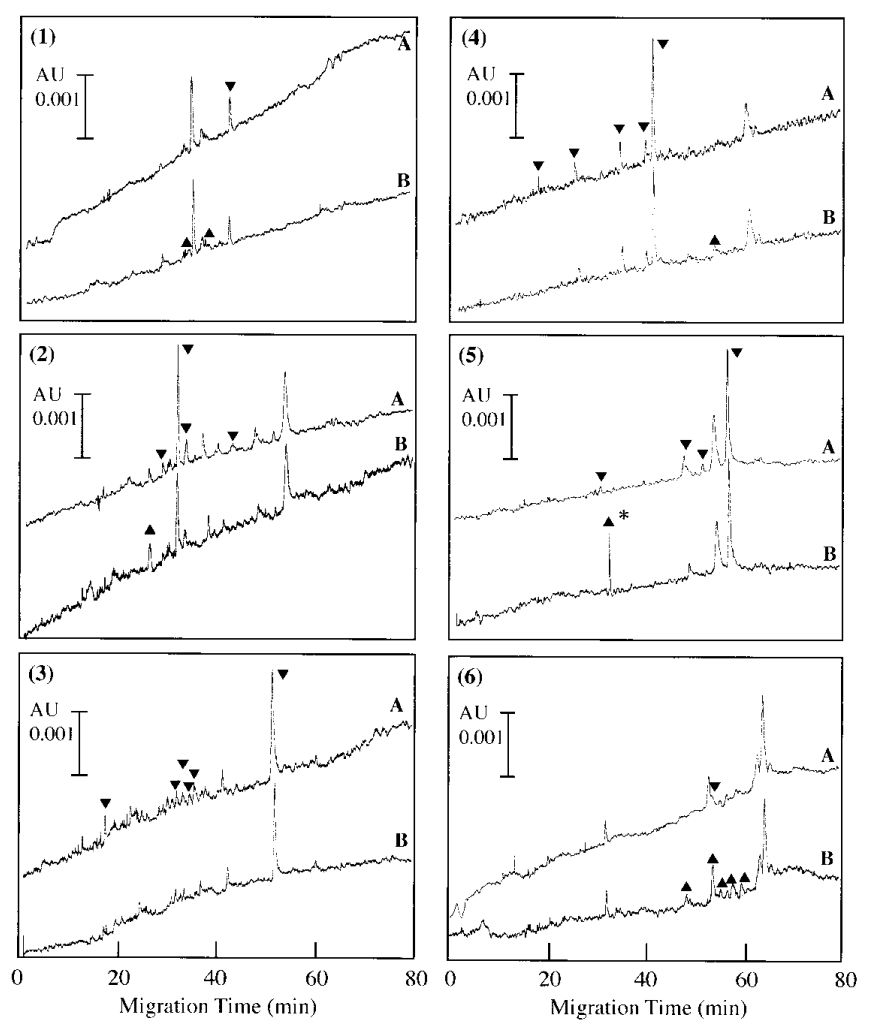

Fig. 3. CE analysis of PCR products derived from RNA of IMR32 neuroblastoma cells in FBS-medium (A) and in GF21-medium (B) after 7 days in culture using three different arbitrary primers (GTACAAGTTCC, GATCATGGTC, and GGAACCAATC) and three 3'anchor primers (oligo-dT-A, oligo-dT-C, and oligo-dT-G). CE conditions are described in the Experimental session. (1) in figure was used the arbitrary primer "GTACAAGTTCC" and the anchor primer "oligo-dT-C" for amplification, (2) was "GTACAAGTTCC" and oligo-dT-A, (3) was "GATCATGGTC" and oligo-dT-C, (4) was "GATCATGGTC" and oligo-dT-G, (5) was "GGAACCAATC" and oligo-dT-A, and (6) was "GGAACCAATC" and oligo-dT-G. A symbol $(\boldsymbol{\nabla})$ on $(\mathrm{A})$ in figure represents peaks that decrease and/or diminish on (B), and the other $(\mathbf{A})$ on (B) shows increasing and/or newly appearing peaks on (B). The identified peaks were reproducible. An asterisk in (5) shows a new peak which is a candidate for differentially expressed gene.

changes, it might also be an important factor that many dominant gene expressions are suppressed in cells cultured in GF21-medium. In any case, these may represent maternal mRNAs, the identity and function of which is almost unknown in the differential cells.

\section{Conclusion}

We have attempted to use molecular sieving CE as an alternative to conventional slab gel electrophoresis for the mRNA differential display. The results shown in figure 3 demonstrate the potential of $\mathrm{CE}$ for mRNA differential display analysis. Furthermore, in molecular sieving CE, micropreparation of characteristic amplicons is possible for further study. Considering the features, it is expected that $\mathrm{CE}$ analysis for the mRNA differential display will be more commonly used in the future.

However, at present, there are still several problems to be solved: (1) Better resolution will be required in the region from low to high molecular weight; (2) the sensitivity of CE must be improved; (3) the difference of mRNA fingerprints between by slab gel electrophoresis and by molecular sieving $\mathrm{CE}$ must be investigated in detail.

At present, we are trying to find solutions to the problem outline above.

\section{References}

1. Williams, J. G. K.; Kubelik, A. R.; Livak, K. J.; Rafalski, J. A.; Tingey, S. V. Nucleic Acids Res. 1990, 18, 6531-6535.

2. Welsh, J.; McClelland, M. Nucleic Acids Res. 1990, 18, 72137218.

3. Welsh, J.; Chada, K.; Dalal, S. S.; Cheng, R.; Ralph, D.; McClelland, M. Nucleic Acid Res. 1992, 20, 4965-4970.

4. Liang, P.; Pardee, A. B. Science 1992, 257, 967-971.

5. Liang, P.; Averboukh, L.; Keyomarsi, K.; Sager, R.; Pardee, A. B. Cancer Res. 1992, 52, 6966-6968.

6. Liang, P.; Averboukh, L.; Pardee, A. B. Nucleic Acids Res. 1993, 21, 3269-3275.

7. Ralph, D.; McClelland, M.; Welsh, J. Proc. Natl. Acad. Sci. USA 1993, 90, 10710-10714.

8. Wong, K. K.; McClelland, M. Proc. Natl. Acad. Sci. USA 1994, 91, 639-643.

9. Ito, T.; Kito, K.; Adati, N.; Mitsui, Y.; Hagiwara, H.; Sakaki, Y. FEBS Lett., 1994, 351, 231-236.

10. Livesey, F. J., Hunt, S. P. Trends Neurosci. 1996, 19, 84-88.

11. Krstulovic, A. M. Capillary Electrophoresis in Life Science, Wiley, J., New York 1997.

12. Camilleri, P., Okafo, G. N., Southan, C., Brown, R. Anal. Biochem. 1991, 198, 36-42.

13. Ishioka, N., Kogure, T., Kurosu, Y. J. Chromatogr. B 1997, 697, 135-140.

14. McCord, B. R., McClure, D. L., Jung, J. M. J. Chromatogr. A 1993, 652, 75-82.

15. Srinivasan, K.; Girard, J. E.; Williams, P.; Roby, R. K.; Weedn, V. W.; Morris, S. C.; Kline, M. C.; Reeder, D. J. J. Chromatogr. A 1993, 652, 83.

16. Williams, P. E.; Marino, M. A.; Del Rio, S. A.; Turni, L.A.; Devaney, J. M. J. Chromatogr. A 1994, 680, 525-540.

17. Belgrader, P.; Devaney, J. M.; Del Rio, S. A.; Turner, K. A.; Weaver, K. R.; Marino, M. A. J. Chromatogr. B 1996, 683, 109-114.

18. Righetti, P. G.; Gelfi, C. Anal. Biochem. 1997, 244, 195-207.

19. Murakami, H.; Masui, H.; Sato, G. H.; Sueoka, N.; Chow, T. P.; Kano-Sueoka, T. Proc. Natl. Acad. Sci. USA 1982, 79, 1158-1162.

20. Shintani, H.; Polonsky, J. Capillary Electrophoresis Applications, Blackie Academic \& Professional, London, 1997; Ch. 7, p 104-117. 